\title{
Magnetic Resonance Imaging versus Computed Tomography in Transient Ischemic Attack and Minor Stroke: The More You See the More You Know
}

\author{
François Moreau a, Negar Asdaghib, e Jayesh Modib, c Mayank Goyal ${ }^{\text {b, } c}$ \\ Shelagh B. Coutts ${ }^{\text {b-d }}$ \\ aDépartement de médecine, Université de Sherbrooke, Sherbrooke, Que., Departments \\ of ${ }^{b}$ Clinical Neurosciences and ${ }^{\mathrm{c}}$ Radiology, and ${ }^{\mathrm{d}}$ Hotchkiss Brain Institute, University of \\ Calgary, Calgary, Alta., and $\mathrm{BC}$ Centre for Stroke and Cerebrovascular Diseases, University of \\ British Columbia, Vancouver, B.C., Canada
}

\section{Key Words}

Transient ischemic attack · Mild stroke - Magnetic resonance imaging · Diffusion-weighted magnetic resonance imaging $\cdot$ Computed tomography

\section{Abstract}

Background: Magnetic resonance imaging (MRI) is proposed as the preferred imaging modality to investigate patients with transient ischemic attack (TIA). This is mainly based on a higher yield of small acute ischemic lesions; however, direct prospective comparisons are lacking. In this study, we aimed to directly compare the yield of acute ischemic lesions on MRI and computed tomography (CT) in the emergency diagnosis of suspected TIA or minor stroke. Methods: Consecutive patients aged 18 years or older presenting with minor stroke (NIHSS $<4$ ) or high-risk TIA and who were examined by a stroke neurologist within $24 \mathrm{~h}$ of symptom onset were prospectively enrolled in the $\mathrm{CATCH}$ study. Patients who had undergone both a baseline $\mathrm{CT}$ and an MRI within $24 \mathrm{~h}$ of symptom onset were included in this substudy. Baseline MRI and CT were interpreted independently to identify an acute ischemic lesion. The rates of acute ischemic lesions on CT and MRI were compared, and the volume of acute ischemic lesions was measured on MRI. In addition, the volume of acute ischemic lesions on MRI was compared between patients who had evidence of acute ischemia on CT and in those who did not. Results: A total of 347 patients were included, 168 with TIAs, 147 with minor strokes and 32 with a final diagnosis of a mimic. Acute ischemic lesions were detected in $39 \%$ of TIAs by 
using MRI versus $8 \%$ by using CT ( $p<0.0001)$ and in $86 \%$ of minor strokes by using MRI versus $18 \%$ by using CT ( $<0.0001$ ). Compared to MRI, CT had a sensitivity of $20 \%$ and a specificity of $98 \%$ in identifying an acute ischemic lesion. The infarct volume on diffusion-weighted MRI was larger in cases where the CT also showed an acute ischemic lesion (median 5.07 $\mathrm{ml}$, IQR 10) as compared to lesions seen only on MRI (median $0.68 \mathrm{ml}$, IQR $1.31, \mathrm{p}<0.0001$ ). Conclusion: MRI is superior to CT in detecting the small ischemic lesions occurring after TIA and minor stroke. Since these lesions are clinically relevant, MRI should be the preferred imaging modality in this setting.

(C) 2013 S. Karger AG, Basel

\section{Introduction}

Multiple studies have shown that over half of the patients with transient ischemic attack (TIA) or minor stroke have evidence of acute ischemic tissue injury on early diffusionweighted imaging (DWI) [1-3]. The sensitivity of DWI is highest if imaging is obtained earlier, preferably within the first $24 \mathrm{~h}$ after symptom onset [4]. Magnetic resonance imaging (MRI) has shown a superior sensitivity over CT in identifying ischemic lesions in the setting of suspected acute ischemic stroke [5]. Furthermore, in one study, it was shown to identify acute ischemic lesions in a third of patients with normal CT after TIA [6]. However, not all patients in this study completed both modalities, and a direct prospective comparison between MRI and CT in a population of patients with TIA or minor stroke is lacking.

The aim of this study was to directly compare the diagnostic yield of MRI and CT imaging in a TIA and minor stroke population.

\section{Methods}

\section{Patients}

Patients were selected from the CATCH study; detailed inclusion criteria have previously been described [7]. Briefly, CATCH is a prospective cohort study of high-risk (focal weakness or speech disturbance lasting $\geq 5 \mathrm{~min}$ ) TIA and minor stroke (NIHSS $<4$ ) patients enrolled between April 2008 and September 2010. Consecutive patients aged 18 years or older presenting with minor stroke or TIA were examined by a stroke neurologist within $24 \mathrm{~h}$ of symptom onset. Detailed baseline clinical and outcome information was prospectively collected from each patient. All patients had undergone a computed tomography (CT) within $24 \mathrm{~h}$ of symptom onset. In a subset of patients, we performed MRI of the brain at baseline and within $24 \mathrm{~h}$ of symptom onset. In this substudy, we included patients who had completed both $\mathrm{CT}$ and MRI within $24 \mathrm{~h}$ of symptom onset for their presenting event.

Patients were further classified as 'final diagnosis of TIA' (focal neurologic symptoms that completely resolved within $24 \mathrm{~h}$ of symptom onset and TIA mimics excluded upon review of all investigations and follow-up data at 90 days), 'final diagnosis of minor stroke' (nondisabling, focal neurologic symptoms lasting more than $24 \mathrm{~h}$ and minor stroke mimics excluded) and 'stroke or TIA mimics'. Overall data for the entire cohort includes all patients from the three categories.

\section{Magnetic Resonance Imaging}

All MRI images were acquired on a 3.0-T GE scanner. MRI sequences included DWI (slice thickness $3.5 \mathrm{~mm}$ and slice spacing $0.0 \mathrm{~mm}$ ) and FLAIR. MRIs were evaluated by a neuroradiologist blind to the CT results. The classification of acute ischemic lesions required hyperin- 
tense signal on DWI with associated hypointensity or isointensity on apparent diffusion coefficient. If a DWI hyperintense lesion was also hyperintense on the apparent diffusion coefficient map, it was classified as a chronic lesion due to T2 shine-through phenomenon. Measurements of the planimetric DWI lesion volume were performed using Quantomo software [8]. DWI hyperintense lesion borders were defined using a semiautomated threshold intensity technique. In this population, we have previously shown a high intra- and interrater reliability in the measurement of small acute DWI lesions [9].

\section{CT Imaging}

All CT imaging was performed on a Siemens 64-slice scanner. A standard axial CT of the whole brain was performed with a sequential (nonhelical) technique at 5-mm slice thickness. Imaging was evaluated by a neuroradiologist who was given clinical information on the presenting event. CT scans were assessed blind to the results of the MRI. Acute ischemic lesions were defined on the CT scans as hypodensity or loss of gray-white matter differentiation using variable window width and center level settings increasing the gray-white matter contrast to optimize sensitivity [10]. Hypodensities darker than the normal white matter were not rated as acute ischemic lesions, since the time from symptom onset was always less than $24 \mathrm{~h}$.

\section{Statistical Analysis}

Statistical analysis was completed with Stata (version 11). Standard descriptive statistics were used for continuous or binomial outcomes as appropriate. The rates of acute ischemic lesions on CT and MRI were compared using McNemar's test, since MRI and CT represent matched pairs for each patient. Distributions of lesion volume were compared using the Wilcoxon rank-sum (Wilcoxon-Mann-Whitney) test.

\section{Results}

A total of 347 patients were included in this study. Baseline characteristics are shown in table 1. Overall, acute ischemic lesions were more common on DWI (193/347: 56\%) than on CT (41/347: 12\%, p < 0.0001, table 2). We found out that 155 of the 306 (51\%) CT-negative patients were positive on DWI-MRI. Considering DWI-MRI as the gold standard, in this study, CT has a sensitivity of 20\% (38 CT-positive patients vs. 193 MRI-positive patients) and a specificity of 98\% (151 CT-negative patients vs. 154 MRI-negative patients). There were 151 MRI-negative patients versus 306 CT-negative patients (49\% negative predictive value for CT). In addition, 38 of 41 patients who had an acute lesion on CT had a concurrent lesion on DWI (93\% positive predictive value for CT).

For the final diagnosis of TIA, the yield of both modalities was lower but a significant difference remained (table 3). Furthermore, 54 of the 155 (35\%) CT-negative patients were positive on DWI (fig. 1). For the final diagnosis of minor stroke, the yield is higher for both modalities and the added yield of MRI is even greater (table 4). A total of 100 of the 120 (83\%) CT-negative patients were positive on DWI.

On DWI, the infarct volume was larger in CT-positive patients (median $5.07 \mathrm{ml}$, IQR 10) compared to CT-negative patients (median $0.68 \mathrm{ml}$, IQR 1.31, p < 0.0001). The median infarct volume $(0.89 \mathrm{ml}$, IQR 2.76$)$ and mean $(2.92 \mathrm{ml}, 95 \% \mathrm{CI} 0.09-12.82)$ of all positive DWI lesions were small and not statistically different for TIA (median $1.13 \mathrm{ml}$, IQR 2.97) and minor stroke (median $0.845 \mathrm{ml}$, IQR 2.53) patients. 


\section{Cerebrovascular. \\ Diseases}

Table 1. Baseline characteristics of 347 patients

\begin{tabular}{l|l}
\hline Cerebrovasc Dis Extra 2013;3:130-136 \\
\hline DOI: $10.1159 / 000355024$ & $\begin{array}{l}\text { ( ) 2013 S. Karger AG, Basel } \\
\text { www.karger.com/cee }\end{array}$ \\
\hline
\end{tabular}

Moreau et al.: Magnetic Resonance Imaging versus Computed Tomography in Transient Ischemic Attack and Minor Stroke: The More You See the More You Know

Age, years

69 (22)

Male gender

205 (59)

TIA at clinical presentation ${ }^{\mathrm{a}}$

$190(55)$

Minor stroke at clinical presentation ${ }^{\mathrm{b}}$

157 (45)

Final diagnosis of TIA

Final diagnosis of minor stroke

$168(48)$

$147(42)$

$32(10)$

58 (107)

Duration of symptoms ${ }^{\mathrm{d}}$, min

Baseline NIHSS if minor stroke

$2(2)$

Diabetes mellitus

$43(12)$

Hypertension

$185(53)$

Atrial fibrillation

25 (7)

55 (16)

Current smoker

5 (5)

15 (12)

$8(11)$

Time from CT to MRI, h

$0.89(2.76)$

Values are medians (IQR) or n (\%). ${ }^{\mathrm{a}}$ Resolved within $24 \mathrm{~h} .{ }^{\mathrm{b}}$ Lasting more than $24 \mathrm{~h} .{ }^{\mathrm{c}}$ Resolved within $24 \mathrm{~h}$ and mimics excluded. ${ }^{\mathrm{d}}$ Duration of symptoms in TIA.

Table 2. Acute ischemic changes in all patients (including mimics) seen on CT and MRI

Table 3. Acute ischemic changes in all patients with a final diagnosis of TIA seen on early CT and early MRI

Table 4. Acute ischemic changes in patients with a final diagnosis of minor stroke seen on early CT and early MRI

\begin{tabular}{llll}
\hline & CT positive & CT negative & Total \\
\hline DWI positive & 38 & 155 & $193(56)$ \\
DWI negative & 3 & 151 & $154(44)$ \\
Total & $41(12)$ & $306(88)$ & $347(100)$ \\
\hline
\end{tabular}

Values are $\mathrm{n}(\%)$. McNemar's $\chi^{2}, \mathrm{p}<0.0001$.

\begin{tabular}{lccc}
\hline & CT positive & CT negative & Total \\
\hline DWI positive & 12 & 54 & $66(39)$ \\
DWI negative & 1 & 101 & $102(61)$ \\
Total & $13(8)$ & $155(92)$ & $168(100)$ \\
\hline
\end{tabular}

Values are $\mathrm{n}(\%)$. McNemar's $\chi^{2}, \mathrm{p}<0.0001$.

\begin{tabular}{lccc}
\hline & CT positive & CT negative & Total \\
\hline DWI positive & 26 & 100 & $126(86)$ \\
DWI negative & 1 & 20 & $21(14)$ \\
Total & $27(18)$ & $120(82)$ & $147(100)$ \\
\hline
\end{tabular}

Values are $\mathrm{n}(\%)$. McNemar's $\chi^{2}, \mathrm{p}<0.0001$ 


\section{Cerebrovascular \\ Diseases}

Fig. 1. CT (a) and MRI (b) of the brain performed on the same day in a TIA patient showing no sign of acute ischemia on CT and a very small area of restricted diffusion on DWI-MRI.

\begin{tabular}{l|l}
\hline Cerebrovasc Dis Extra 2013;3:130-136 \\
\hline DOI: $10.1159 / 000355024$ & $\begin{array}{l}\text { @ 2013 S. Karger AG, Basel } \\
\text { www.karger.com/cee }\end{array}$ \\
\hline
\end{tabular}

Moreau et al.: Magnetic Resonance Imaging versus Computed Tomography in Transient Ischemic Attack and Minor Stroke: The More You See the More You Know
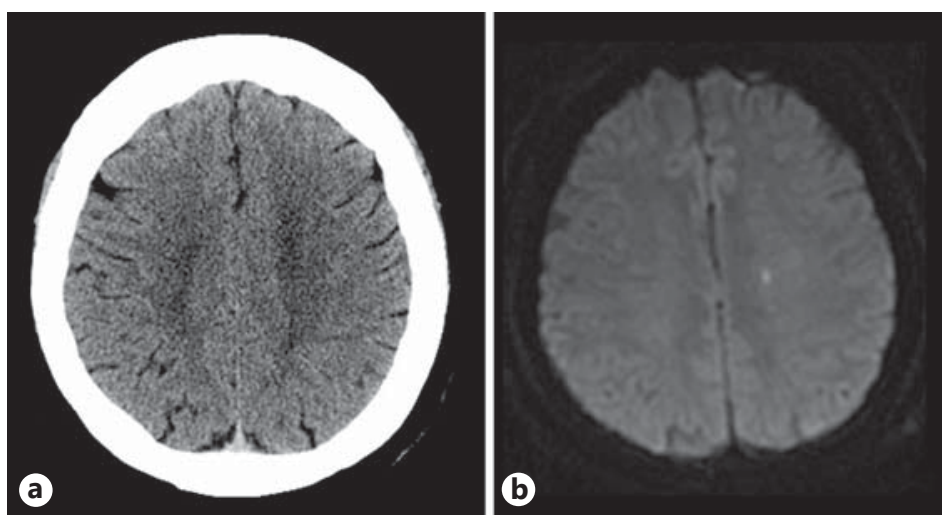

\section{Discussion}

The current study represents the first prospective direct comparison between acute CT scan findings and urgent MRI imaging. We found out that MRI imaging has a much higher yield than CT in identifying acute ischemic lesions in the setting of a clinical presentation of TIA or minor stroke. We also observed that the lesions missed by CT, but identified by MRI had a smaller infarct volume.

Previous work has shown that DWI-MRI identifies acute ischemia in approximately $35-50 \%$ of patients presenting with TIA or minor stroke [1,11-17], and that, in this population, acute ischemic changes are less frequent (10\%) on CT. In this study, we found out that $50 \%$ of patients who were negative on CT had evidence of an acute lesion on MRI. Forster et al. [6] recently reported that 33\% of TIA patients with a normal baseline CT had evidence of acute infarction on MRI. We showed results comparable to those of Forster et al. [6] for the TIA subgroup and demonstrated an even larger proportion of acute infarction on MRI after negative CT in the minor stroke population. The yield of CT and MRI imaging for detection of acute ischemic changes is much higher in patients who present with disabling ischemic stroke [5]. This is thought to be mainly due to the larger infarct size [18]. Our results support this finding, as the sensitivity of CT alone in identifying ischemic lesions less than $1 \mathrm{ml}$ in volume was extremely poor.

A limitation of our study is that the CT and MRI studies were not conducted at the same time, with the time from symptom onset to imaging being longer for MRI compared to CT. Since early ischemic changes become more conspicuous over time, on imaging this potentially introduces bias in favor of MRI. The relatively short time span (median of $8 \mathrm{~h}$ ) between the two studies reduces the likelihood of recurrent events that might affect the results.

This study supports the use of MRI instead of CT for a patient presenting acutely with a TIA or minor stroke because of the superior yield of ischemia in small volume lesions. Previous literature has shown that the finding of an acute ischemic lesion on MRI adds useful clinical information. Firstly, the presence of an ischemic lesion in the brain causes symptoms in the patient. Secondly, location and distribution have diagnostic value in relation to the stroke mechanism [19], but localization on clinical grounds alone in the setting of transient symptoms is far from perfect [20]. Finally, an acute ischemic lesion on DWI in the investigation of TIA and minor stroke has prognostic value as a strong predictor of recurrent stroke $[1,15,16$, 21-23]. 


\section{Cerebrovascular Diseases}

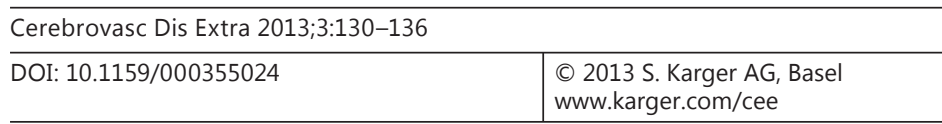

Moreau et al.: Magnetic Resonance Imaging versus Computed Tomography in Transient Ischemic Attack and Minor Stroke: The More You See the More You Know

\section{Acknowledgements}

S.B.C. received salary support from the Alberta Innovates-Health Solutions and the Heart and Stroke Foundation of Canada's Distinguished Clinician Scientist award, supported in partnership with the Canadian Institute of Health Research (CIHR), the Institute of Circulatory and Respiratory Health and AstraZeneca Canada Inc.

The study received funding from the Canadian Institute of Health Research (CIHR) and a Pfizer Cardiovascular research award.

\section{Disclosure Statement}

The authors have no conflicts of interest to disclose.

\section{References}

1 Merwick A, Albers GW, Amarenco P, Arsava EM, Ay H, Calvet D, Coutts SB, Cucchiara BL, Demchuk AM, Furie KL, Giles MF, Labreuche J, Lavallee PC, Mas JL, Olivot JM, Purroy F, Rothwell PM, Saver JL, Sheehan OC, Stack JP, Walsh C, Kelly PJ: Addition of brain and carotid imaging to the $\mathrm{ABCD}^{2}$ score to identify patients at early risk of stroke after transient ischaemic attack: a multicentre observational study. Lancet Neurol 2010;9:10601069.

-2 Giles MF, Albers GW, Amarenco P, Arsava EM, Asimos AW, Ay H, Calvet D, Coutts SB, Cucchiara BL, Demchuk AM, Johnston SC, Kelly PJ, Kim AS, Labreuche J, Lavallee PC, Mas JL, Merwick A, Olivot JM, Purroy F, Rosamond WD, Sciolla R, Rothwell PM: Early stroke risk and ABCD2 score performance in tissue- vs time-defined TIA: a multicenter study. Neurology 2011;77:1222-1228.

-3 Coutts SB, Hill MD, Simon JE, Sohn CH, Scott JN, Demchuk AM: Silent ischemia in minor stroke and TIA patients identified on MR imaging. Neurology 2005;65:513-517.

-4 Moreau F, Modi J, Almekhlafi M, Bal S, Goyal M, Hill MD, Coutts SB: Early magnetic resonance imaging in transient ischemic attack and minor stroke: do it or lose it. Stroke 2013;44:671-674.

-5 Chalela JA, Kidwell CS, Nentwich LM, Luby M, Butman JA, Demchuk AM, Hill MD, Patronas N, Latour L, Warach S: Magnetic resonance imaging and computed tomography in emergency assessment of patients with suspected acute stroke: a prospective comparison. Lancet 2007;369:293-298.

-6 Forster A, Gass A, Kern R, Ay H, Chatzikonstantinou A, Hennerici MG, Szabo K: Brain imaging in patients with transient ischemic attack: a comparison of computed tomography and magnetic resonance imaging. Eur Neurol 2012;67:136-141.

7 Coutts SB, Modi J, Patel SK, Demchuk AM, Goyal M, Hill MD: CT/CT angiography and MRI findings predict recurrent stroke after transient ischemic attack and minor stroke: results of the prospective catch study. Stroke 2012;43:1013-1017.

8 Kosior JC, Idris S, Dowlatshahi D, Alzawahmah M, Eesa M, Sharma P, Tymchuk S, Hill MD, Aviv RI, Frayne R, Demchuk AM: Quantomo: validation of a computer-assisted methodology for the volumetric analysis of intracerebral haemorrhage. Int J Stroke 2011;6:302-305.

-9 Steffenhagen N, Campos CR, Poppe AY, Khan F, Kosior JC, Demchuk AM, Hill MD, Coutts SB: Reliability of measuring lesion volumes in transient ischemic attack and minor stroke. Stroke 2010;41:814-816.

10 Lev MH, Farkas J, Gemmete JJ, Hossain ST, Hunter GJ, Koroshetz WJ, Gonzalez RG: Acute stroke: improved nonenhanced CT detection - benefits of soft-copy interpretation by using variable window width and center level settings. Radiology 1999;213:150-155.

-11 Inatomi Y, Kimura K, Yonehara T, Fujioka S, Uchino M: DWI abnormalities and clinical characteristics in TIA patients. Neurology 2004;62:376-380.

-12 Easton JD, Saver JL, Albers GW, Alberts MJ, Chaturvedi S, Feldmann E, Hatsukami TS, Higashida RT, Johnston SC, Kidwell CS, Lutsep HL, Miller E, Sacco RL: Definition and evaluation of transient ischemic attack: a scientific statement for healthcare professionals from the American Heart Association/American Stroke Association Stroke Council; Council on Cardiovascular Surgery and Anesthesia; Council on Cardiovascular Radiology and Intervention; Council on Cardiovascular Nursing; and the Interdisciplinary Council on Peripheral Vascular Disease. The American Academy of Neurology affirms the value of this statement as an educational tool for neurologists. Stroke 2009;40:2276-2293.

13 Kidwell CS, Alger JR, Di Salle F, Starkman S, Villablanca P, Bentson J, Saver JL: Diffusion MRI in patients with transient ischemic attacks. Stroke 1999;30:1174-1180. 
14 Giles MF, Albers GW, Amarenco P, Arsava MM, Asimos A, Ay H, Calvet D, Coutts S, Cucchiara BL, Demchuk AM, Johnston SC, Kelly PJ, Kim AS, Labreuche J, Lavallee PC, Mas JL, Merwick A, Olivot JM, Purroy F, Rosamond WD, Sciolla R, Rothwell PM: Addition of brain infarction to the ABCD2 score (ABCD2I): a collaborative analysis of unpublished data on 4,574 patients. Stroke 2010;41:1907-1913.

15 Calvet D, Touze E, Oppenheim C, Turc G, Meder JF, Mas JL: DWI lesions and TIA etiology improve the prediction of stroke after TIA. Stroke 2009;40:187-192.

-16 Asimos AW, Rosamond WD, Johnson AM, Price MF, Rose KM, Murphy CV, Tegeler CH, Felix A: Early diffusion weighted MRI as a negative predictor for disabling stroke after ABCD2 score risk categorization in transient ischemic attack patients. Stroke 2009;40:3252-3257.

17 Rovira A, Rovira-Gols A, Pedraza S, Grive E, Molina C, Alvarez-Sabin J: Diffusion-weighted MR imaging in the acute phase of transient ischemic attacks. AJNR Am J Neuroradiol 2002;23:77-83.

18 Castle J, Mlynash M, Lee K, Caulfield AF, Wolford C, Kemp S, Hamilton S, Albers GW, Olivot JM: Agreement regarding diagnosis of transient ischemic attack fairly low among stroke-trained neurologists. Stroke 2010; 41:1367-1370.

19 Ay H, Furie KL, Singhal A, Smith WS, Sorensen AG, Koroshetz WJ: An evidence-based causative classification system for acute ischemic stroke. Ann Neurol 2005;58:688-697.

-20 Flossmann E, Redgrave JN, Briley D, Rothwell PM: Reliability of clinical diagnosis of the symptomatic vascular territory in patients with recent transient ischemic attack or minor stroke. Stroke 2008;39:2457-2460.

21 Purroy F, Begue R, Quilez A, Pinol-Ripoll G, Sanahuja J, Brieva L, Seto E, Gil MI: The California, ABCD, and unified $\mathrm{ABCD} 2$ risk scores and the presence of acute ischemic lesions on diffusion-weighted imaging in TIA patients. Stroke 2009;40:2229-2232.

-22 Sylaja PN, Coutts SB, Subramaniam S, Hill MD, Eliasziw M, Demchuk AM: Acute ischemic lesions of varying ages predict risk of ischemic events in stroke/TIA patients. Neurology 2007;68:415-419.

-23 Ay H, Arsava EM, Johnston SC, Vangel M, Schwamm LH, Furie KL, Koroshetz WJ, Sorensen AG: Clinical- and imaging-based prediction of stroke risk after transient ischemic attack: The CIP model. Stroke 2009;40:181186. 